\title{
CAPITAL SOCIAL E RELAÇÕES PÚBLICAS NO ENOTURISMO: ESTUDO DE CASO DE UM ROTEIRO ENOTURÍSTICO DA SERRA GAÚCHA
}

EDIANE BASSANESI

UNIVERSIDADE DE CAXIAS DO SUL CAXIAS DO SUL, RIO GRANDE DO SUL, BRASIL EDIBASSANESI@HOTMAIL.COM

EDUARDO ROBINI DA SILVA UNIVERSIDADE DE CAXIAS DO SUL CAXIAS DO SUL, RIO GRANDE DO SUL, BRASIL EDUARDOROBINI@GMAIL.COM

FERNANDA PAULETTO D'ARRIGO UNIVERSIDADE DE CAXIAS DO SUL CAXIAS DO SUL, RIO GRANDE DO SUL, BRASIL FERNANDA.DARRIGO@GMAIL.COM

ANA CRISTINA FACHINELLI UNIVERSIDADE DE DEUSTO DEUSTO, ESPANHA AFACHINELLI@GMAIL.COM

HTTP://DX.DOI.ORG/10.5902/2316882X21578 
CAPITAL SOCIAL E RELAÇÕES PÚBLICAS NO ENOTURISMO: ESTUDO DE CASO DE UM ROTEIRO ENOTURÍSTICO DA SERRA GAÚCHA

Resumo: O trabalho busca explorar o papel das atividades de Relações Públicas na formação de capital social em associações enoturísticas. A pesquisa trata-se de um estudo de caso, ambientado no roteiro enoturístico Compassos Mérica-Mérica, na Serra Gaúcha. A pesquisa qualitativa exploratória mostrou que a comunicação é fundamental para o desenvolvimento do Capital Social no campo do enoturismo.

Palavras chaves: Enoturismo; Capital Social; Relações Públicas; Comunicação.

CAPITAL SOCIAL Y LAS RELACIONES PÚBLICAS EN EL ENOTURISMO: UN ESTUDIO DE CASO DE UNA RUTA ENOTURÍSTICA DE LA SERRA GAÚCHA - BRAZIL

Resumen: El trabajo tiene como objetivo explorar el papel de las actividades de relaciones públicas en la formación de capital social en las asociaciones enoturísticas. La investigación es un estudio de caso, conducido en la ruta del enoturismo Mérica-Mérica - Serra Gaúcha, Brazil. La investigación cualitativa exploratoria mostró que la comunicación es clave para el desarrollo del capital social en el campo del turismo del vino.

Palabras clave: Enoturismo; Capital social; Relaciones públicas; Comunicación.

SOCIAL CAPITAL AND PUBLIC RELATIONS IN ENOTOURISM: A CASE STUDY OF A WINE TOURISM ROUTE OF THE SERRA GAÚCHA - BRAZIL

Abstract: The study aims to explore the role of public relations activities in the formation of social capital in enoturísticas associations. The research it is a case study, carried out in the Mérica-Mérica - Serra Gaúcha, Brazil. The exploratory qualitative research showed that communication is key to the development of Social Capital in the wine tourism field.

Keywords: Wine Tourism. Share capital. Public relations. Communication. 


\section{Introdução}

Do ponto de vista social, entende-se que todo cidadão é parte da sobrevivência dos sistemas, e pela sua interação consciente com o meio e com os demais no convívio social, cria-se o capital social (MARTI, 2004). Desta forma, o capital social envolve as circunstâncias nas quais os indivíduos podem se valer da sua participação em grupos e redes para atingir metas e benefícios. Além de contribuição individual, o capital social é visto como componente da ação coletiva, ativando redes sociais. Ele representa um conjunto de elementos com os quais um grupo social garante sua reprodução, incluindo o capital econômico, cultural e simbólico (BORDIEU, 2001).

Como campo teórico, o capital social foi retratado na literatura em duas vertentes teóricas. A primeira delas define o capital social sob uma lente sociológica. Esta vertente se refere aos recursos - capitais (apoio, ideias, informações) que os indivíduos são capazes de conquistar ao se relacionar com os demais (social). Já a outra vertente, mais próxima da ciência política, a qual se refere à natureza e a extensão das redes informais nas sociedades cívicas. Ou seja, o capital social é usado com um termo conceitual para caracterizar as relações entre membros de uma comunidade (GROOTAERT, 2004, MARTI, 2004).

Em ambas as vertentes se destaca o papel da interação do indivíduo com o seu meio e com os demais, como forma de criação e valor. Neste contexto, destaca-se o papel do profissional de Relações Públicas, na função de planejar, implantar e desenvolver o processo total da comunicação para gerir os relacionamentos (GRUNING, 2013) pode promover o capital social de organizações, associações, comunidades, localidades e demais sistemas.

Traços de capital social podem ser identificados em iniciativas na área de enoturismo e estão na base do desenvolvimento socioeconômico em regiões nas quais esse setor tem se desenvolvido. Macke, Genari e Faccin (2012) identificaram que o capital social tem tido influência no desenvolvimento de regiões vitivinícolas associadas ao enoturismo. Desta forma, o capital social é tratado como uma forma de alavancar o desempenho empresarial, através das interações sociais e relações existentes entre eles no campo de empresas de enoturismo.

O enoturismo é caracterizado pela visitação aos vinhedos, cantinas,

Rev.Cad.Comun. Santa Maria, v.20, n.3, art 6, p.127 de 145, set/dez.2016 
festivais vinícolas e exposições de vinhos por aqueles cujo gosto pelo vinho e uva e/ou pelo conhecimento das características de uma região vinícola. Assim, o vinho é percebido como um atrativo motivacional para os visitantes, enquanto que, para a indústria vinícola, o enoturismo é uma forma de construir relações com os clientes (HALL, 2004). No enoturismo, percebe-se a construção de capital social através da interação gerada na rede social dos empreendimentos vitivinícolas em associações. As associações nutrem benefícios para os empreendimentos através da facilidade da divulgação do conhecimento, a existência de um ambiente de confiança e cooperação e a busca por referências comuns, bem como objetivos partilhados. Assim, as associações buscam, por meio da formação da capital social, vantagens competitivas para o seu crescimento.

O presente artigo buscou explorar o papel das atividades de Relações Públicas na formação de capital social em associações enoturísticas. Para isso, foi realizada a revisão da fundamentação teórica do capital social, e das atividades de relações públicas. Logo após apresenta-se o capítulo de metodologia de pesquisa, a análise dos resultados e por fim as considerações finais do trabalho.

\section{Capital social}

Por sua natureza, o ser humano é visto como um ser social, uma vez que este estabelece relações com seu ambiente e com outros indivíduos ao seu redor. Assim, em linhas gerais, o capital social é a partilha e experiências e impressões, gerando valor para sua comunidade e todos seus componentes (ARAÚJO, 2010). A expressão "capital social” foi empregada em sua primeira vez por HANIFAN, (1916), o qual definiu como um conjunto de relações sociais marcadas pela camaradagem, simpatia e boa vontade (MATTOS, 2009).

Entretanto, a primeira análise sistemática do conceito de capital social surgiu no campo da sociologia, no artigo "Le capital social: notes provisoires” de BOURDIEU(1980). Por definição, o capital social é um atributo individual dentro de um contexto social, e é definido como "o conjunto de recursos atuais e potenciais que estão ligados à posse de uma rede durável de relações mais ou menos institucionalizadas de conhecimento e reconhecimento mútuo" (BOURDIEU, 2001, p. 187). De acordo com o autor, o conceito de capital social está diretamente ligado ao conceito de capital

Rev.Cad.Comun. Santa Maria, v.20, n.3, art 6, p.128 de 145, set/dez.2016 
cultural, pois o volume de capital social seria determinado pela extensão das redes cívicas que o indivíduo pode mobilizar e do capital (econômico, cultural e simbólico) que se é apropriado nas relações com os outros. Neste ponto de vista, o capital social seria um atributo para o indivíduo que está inserido no contexto social.

Em diferente perspectiva, Coleman (1990) propõe que o capital social deve ser concebido como um bem público, ou seja, algo diretamente relacionado à estrutura das relações entre os indivíduos. Mais tarde, ele enfatiza que o capital social não se situa nem nos meios de produção e nem nos indivíduos, mas nas redes sociais densas que garantem a confiança nas estruturas sociais e permitem a geração de solidariedade (COLEMAN, 1990, p. 302). De modo geral, o conceito de capital social atingiu ampla repercussão após serem publicados os estudos de Robert Putnam. Caracterizado como uma relação de trocas, PUTMAN (2002) propõe que o capital social está na formação de associações entre grupos que pertencem à determinada estrutura, que procuram a melhor forma de atingir o êxito em suas ações de cooperação.

Mais, além o capital pode ser estimulado, uma vez que se cria condições mais propícias para o seu desenvolvimento através de políticas públicas. Se concebido como processo dinâmico de relações sociais, o capital social está ligado ao aprendizado interativo e à cooperação, a capacidade de uma comunidade criar estratégias que facilitam as ações coletivas (ALBAGLI; MACIEL, 2003). Assim, capital social diz respeito à associação, ou seja: o capital pertence a uma coletividade ou a uma comunidade, pois ele é compartilhado e não pertence somente a indivíduos (MILANI, 2003). Dessa forma, o sentido de capital social indica que os recursos são compartilhados não apenas nos níveis da família e indivíduo, mas também nos níveis de grupos e sociedades.

De acordo com Fukyama (1996), para se adquirir capital social é necessária à prática de normas morais comuns a uma determinada comunidade, incluindo-se aí as virtudes "lealdade", "honestidade" e "confiabilidade". Assim, a cooperação sem confiança entre os componentes de um grupo só ocorrerá sob um sistema de regras e regulamentos, o que geram custos transacionais, já que tem que ser negociados, acordados e litigiados (FUKUYAMA, 1996). As virtudes sociais, incluindo o cooperativismo e o senso de dever em relação aos outros, são importantes para desenvolver as virtudes individuais, e tem recebido menos atenção nas discussões so-

Rev.Cad.Comun. Santa Maria, v.20, n.3, art 6, p.129 de 145, set/dez.2016 
CADERNOS DE COMUNICAÇÃO

UNIVERSIDADE FEDERAL DE SANTA MARIA

bre a formação do capital social.

\section{Capital social e relações públicas}

Apesar de ter raízes na sociologia, o capital social tem atraído mais atenção recentemente para as disciplinas como gestão de negócios, ciências políticas e Relações Públicas (RP). Woolcock (2010) expõe que o capital social tem a capacidade de servir como uma extensão das RP pelo fato de medir valores intangíveis, como, por exemplo, relacionamentos, reputação e confiança. O capital social é geralmente visto como um resultado de poder em ativos que incluem reputações favoráveis; aumento da confiança, democracia e governança interna e externa.

As atividades de RP têm sido cada vez mais atribuídas à gestão de relacionamento. Uma definição comum é de que ela é a função de gestão que estabelece e mantém relações mutuamente benéficas entre uma organização e seus públicos. (DODD; BRUMMETTE; HAZLETON, 2015). Ihlen (2005) sugere que como a literatura de RP tornou-se mais centrada no relacionamento, a quantidade e a qualidade das relações de uma organização devem ser percebidas como capital social. O capital social é, portanto, uma preocupação central para os RPs interna e externamente nas organizações. Em complemento, Botan e Hazleton (2006) defendem que os profissionais de RP são aqueles que têm a capacidade de cultivar, manter e investir em capital social para as suas organizações. Na mesma direção, Dodd, Brummette e Hazleton (2015) denominaram a função de RPs como "ampliador de fronteiras", uma vez que este profissional liga a organização aos elementos no ambiente, na sua maioria das vezes no intercâmbio de informações. Dessa forma, são coordenadas atividades que reduzem a incerteza. A equipe da organização de adapta às necessidades e expectativas do ambiente, e o ambiente se adapta à organização. Com isso, o profissional de RP pode ajudar a construir o capital social fora da organização, bem como proporcionar ligações com o ambiente externo que permitam que a organização se beneficie de uma rede de recursos disponíveis na comunidade em geral (DODD; BRUMMETTE; HAZLETON, 2015).

De acordo com Yang e Taylor (2013), a formação de capital social é um dos caminhos pelos quais a profissão de RP contribui para a sociedade. Essa contribuição está na divulgação de informações e a forma de facilitar as relações o qual PUTMAN (2002) chamava de conexões cívicas vigoro-

Rev.Cad.Comun. Santa Maria, v.20, n.3, art 6, p.130 de 145, set/dez.2016 
sas. Assim, uma das funções dos RPs é criar e compartilhar informações entre grupos e redes sociais, já que este profissional é responsável por fornecer subsídios de informação. E o capital social é um resultado desta produção de informações, pois os públicos que são informados são mais propensos a se envolver em questões sociais e participação da sociedade civil, contribuindo, dessa forma para a acumulação do capital social (HABERMAS, 1991).

Esse capital, diferente do capital econômico privado, cria um bem público que beneficia muitos membros de uma sociedade. Existe o benefício mesmo para aqueles que não estavam envolvimentos em uma atividade ou relacionamento. Ainda, a abordagem do tema do capital social refere-se aos laços sociais, uma vez que o capital social pressupõe a existência de laços de dependência recíproca, embasados em comunicação entre os envolvidos nas redes (MATTOS, 2009). Dessa forma, verificamos que a comunicação é parte essencial para o desenvolvimento de Capital Social. Neste contexto, o profissional de RP possui um campo diversificado para sua atuação.

\section{Enoturismo: compreensão contextual}

O enoturismo é caracterizado pela visitação aos vinhedos, cantinas, festivais vinícolas e exposições de vinhos por aqueles cujo gosto pelo vinho e uva e/ou pelo conhecimento das características d uma região vinícola. Assim, o vinho é percebido como um atrativo motivacional para o vinho, enquanto que, para a indústria vinícola, o enoturismo é uma forma de construir relações com os clientes (HALL, 2004).

O início do processo de transformação do vinho em um evento cultural, e a ideia de lançá-lo como produto turístico, na Europa, data de 1993 na Itália, do Movimento Turismo del Vinho (MTV), uma associação italiana que criou a ideia de "Cantina Aberta" (VALDUGA, 2014). Os produtores que aderiram à iniciativa se empenham em acolher os visitantes para uma degustação guiada na cantina. Esse movimento ganhou repercussão, e sua realização tornou-se um evento mundial chamado Wine Day.

O turismo vitivinícola já foi definido como a "arte de viver", repleto de prazeres (DUBRULE, 2007), bem como um patrimônio cultural por se tratar, a herança recebida pelas gerações passadas (DALLANHOL; TONINI, 2012). O enoturismo é uma forma de turismo de interesse específico 
e propuseram um modelo em que as viagens são motivadas pelo destino (a região vitivinícola), pela atividade (a degustação de vinhos), ou ambos. A abordagem dos autores sobre o enoturismo desconsidera o tempo das viagens, aceitando como enoturistas tantos os excursionistas como os visitantes que permanecem mais de 24 horas no destino (HALL, 2004).

O ambiente da produção do vinho mescla a motivação dos visitantes fazendo com que o enoturismo contemple um conjunto de elementos. Assim, o enoturismo é entendido pelo turista conforme seus paradigmas culturais, parte do processo de expectativas e desejos ao chegar aos destinos, o que também é responsável por construir a visão acerca do produto turístico (CHARTERS; ALI-KNIGHT, 2002).

\section{Metodologia}

Para os objetivos propostos no trabalho, realizou-se uma pesquisa de natureza qualitativa, com objetivo exploratório e descritivo, tendo como estratégia de pesquisa o estudo de caso. Nos últimos anos a pesquisa qualitativa tem vivido um período de crescimento e diversificação inéditos ao se tornar uma proposta de pesquisa consolidada e respeitada em diversas disciplinas e contextos (GIBBS, 2009). Esse tipo de evidencia que a pesquisa qualitativa é uma atividade que posiciona o observador no mundo. Ela consiste em um conjunto de práticas interpretativas e materiais que tornam o mundo visível (FLICK, 2009). Como técnica de coleta de dados, foi utilizado entrevistas semi-estruturadas, as quais elaboradas a partir de um roteiro criado a partir da literatura, mas que dá espaço a percepção dos entrevistados (FLICK, 2009).

Para atingir os objetivos propostos, foi utilizado o estudo de caso e como instrumentos de coleta de dados entrevistas. Segundo Yin (2005), o estudo de caso é uma investigação empírica, um método que abrange planejamento, técnicas de coleta de dados e análise das informações (YIN, 2005). O caso é apresentado no capítulo a seguir.

\section{Campo de estudo e participantes do estudo}

Para realização do estudo de caso do presente artigo foi escolhido o Roteiro Turístico Compassos da Mérica Mérica, na Serra Gaúcha. O roteiro é uma associação com nove empreendimentos localizados na cidade de Flo-

Rev.Cad.Comun. Santa Maria, v.20, n.3, art 6, p.132 de 145, set/dez.2016 
res da Cunha, distribuídas nas comunidades de São Roque, Nossa Senhora do Carmo, Nossa Senhora do Bom Conselho e São Vítor.

A associação foi criada em 2010 por proprietários dos empreendimentos vitivinícolas da localidade. O objetivo inicial da fundação foi à obtenção de auxílios para fins comerciais, como compras de insumos e matéria prima. Posteriormente, foi idealizado o roteiro turístico onde cada empreendimento definiu qual serviço seria prestado. Em 2012, após o desenvolvimento do projeto do roteiro, foram iniciados os trabalhos de visitação. Iniciando com poucos recursos, fatores como a cooperação e a confiabilidade foram essenciais para o sucesso do mesmo.

Os participantes deste estudo foram 9 (nove) empresas vinculadas ao Compassos da Mérica Mérica, selecionados pela posição de liderança que ocupam nas empresas participantes do estudo. Os entrevistados são apresentados na Imagem 1.

Imagem 1 - Participantes da Pesquisa

\begin{tabular}{|c|c|c|}
\hline Entrevistado & Identificação & Atividade \\
\hline 1 & A.M. & Vinícola \\
\hline 2 & C.G. & Vinícola \\
\hline 3 & C.V. & Vinícola \\
\hline 4 & V.V.E. & Vinícola \\
\hline 5 & V.V.I. & Vinícola \\
\hline 6 & V.P. & Vinícola \\
\hline 7 & B.O. & Propriedade agrícola \\
\hline 8 & F.M & Propriedade agrícola \\
\hline 9 & J.B. & Propriedade agrícola \\
\hline
\end{tabular}

Fonte: Elaborada pelos autores.

A análise dos resultados seguiu a técnica de análise de conteúdo (FLICK, 2009), sendo que as categorias de análise foram inicialmente definidas a partir da literatura, sendo nomeadas como Macro categorias. As Macro Categorias relacionadas à comunicação foram desenvolvidas para investigar questionamentos correspondentes à atuação do profissional de Relações Públicas no Roteiro Turístico Compassos da Mérica Mérica. Elas foram descritas em: Desenvolvimento da Comunicação (MATTOS, 2009), bem como as Características da Comunicação; Ferramentas de Comunicação, e Capital Social (BORDIEU, 2001; PUTNAM, 2002; COLEMAN, 1990). Na Imagem 2, são apresentadas as macro categorias.

Rev.Cad.Comun. Santa Maria, v.20, n.3, art 6, p.133 de 145, set/dez.2016 

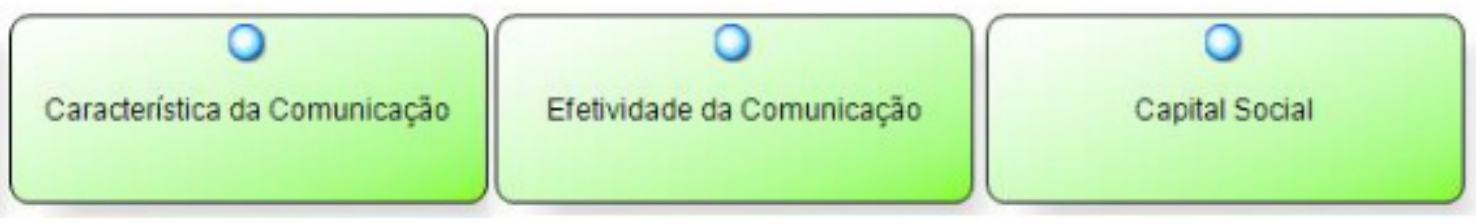

Imagem 2 - Macro categorias do estudo

Fonte: Elaborada pelos autores.

As Ferramentas de Comunicação são instrumentos que auxiliam na composição de qualquer empreendimento, e procuram facilitar a comunicação, a fim de que esta seja efetiva. No roteiro turístico Compassos da Mérica Mérica, procura-se verificar através das entrevistas realizadas, quais são os principais meios de comunicação utilizados entre os associados. As ferramentas de comunicação fazem relação com as Características da Comunicação - que nos informa se esses meios utilizados no Roteiro são formais ou informais.

Uma organização alcança a sua efetividade no processo de comunicação, quando identifica os fatores que contribuem para a eficiência do objetivo traçado. A categoria Efetividade da Comunicação aborda os itens: Resolução de problemas, Relacionamento, Frequência de Comunicação e Desenvolvimento de comunicação. Sendo estes pontos, importantes estratégias utilizadas para que a comunicação flua de forma enérgica. Procurou-se identificar através destes itens abordados na entrevista, se a comunicação dentro do Roteiro Compassos da Mérica Mérica está se desenvolvendo de maneira efetiva.

A última macro categoria, denominada Capital Social, dividiu-se nas subcategorias: Objetivo Comum, Democracia, Confiança e Comprometimento. O Capital Social tem origem e resultado através de ações comunicativas, e é um conjunto de recursos atuais e potenciais que estão ligados a uma rede durável de relações (BORDIEU, 2001).

\section{Análise e resultados}

Em relação as macro categorias Ferramentas de Comunicação e Características da Comunicação, procurou-se abordar, através da análise das entrevistas, como é realizada a comunicação no Roteiro Turístico 
Compassos da Mérica Mérica. Considerou-se a comunicação formal (comunicação realizada através de ferramentas documentadas e padronização) ou informal (comunicação realizada de maneira mais coloquial e simples).

Verificou-se na citação dos entrevistados duas principais ferramentas de comunicação: os integrantes do Roteiro desenvolveram um grupo no de um aplicativo de celular para envio de mensagens instantâneas), caracterizando a aplicação informal, e a transmissão de informações através de e-mail, onde se caracteriza o uso formal.

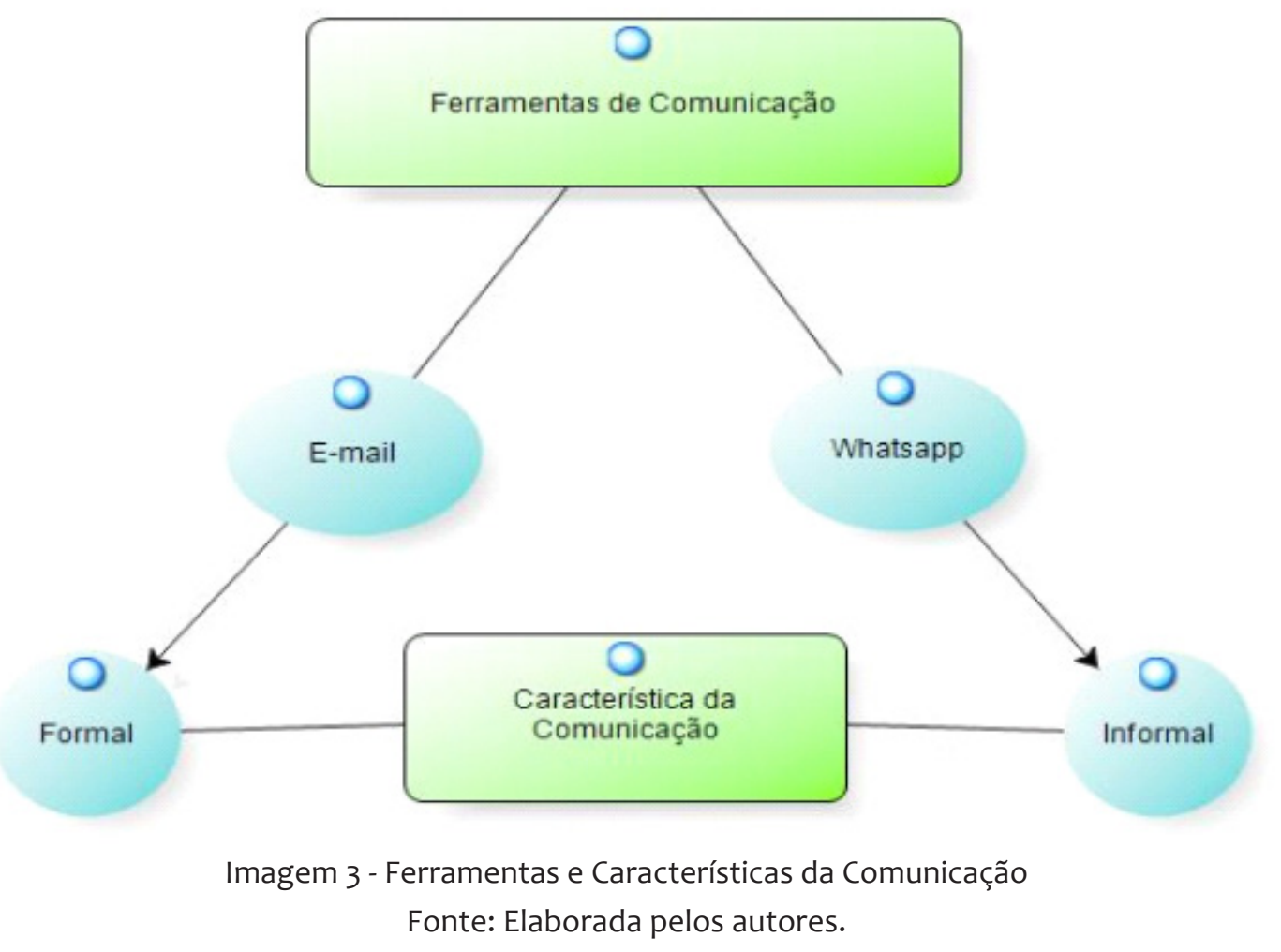

Os integrantes do roteiro, em sua grande maioria, disseram utilizar com maior frequência a ferramenta informal de comunicação, pois, através dela, o contato é mais rápido. Conseguem manter um contato praticamente diário, isso transforma a comunicação mais eficiente. Por tratar-se de um grupo pequeno, sem muitas formalidades, é possível verificar que todos os integrantes conseguem ter acesso e buscam estar cientes de tudo que está acontecendo no roteiro.

Através da análise de conteúdo das entrevistas e a triangulação de dados, nota-se que os integrantes do roteiro utilizam ferramentas formais e informais de comunicação. Como ferramenta informal de comunicação o grupo reporta o uso de um aplicativo de troca de mensagens

Rev.Cad.Comun. Santa Maria, v.20, n.3, art 6, p.135 de 145, set/dez.2016 
como ferramenta. Essa ferramenta de comunicação foi abordada por ser a mais eficiente, tendo em vista que é uma maneira rápida de se comunicarem e obter retorno dos demais. Nota-se que, por ser um roteiro pequeno, e todos os integrantes terem algum laço entre eles (sendo familiar ou simplesmente pelo convívio por serem vizinhos) a forma informal de se comunicar é maior.

Entrevistado 1 explana: “[...] tratamos de assuntos da associação muitas vezes em conversas do aplicativo de mensagens on-line, onde temos um grupo que podemos manter um contato mais direto", e Entrevistado $5 \mathrm{com}$ plementa: "A comunicação é bastante efetiva por meio de ferramentas de comunicação digital”.

A formalidade fica expressa através de registros de e-mail, onde os registros ficam documentados para posterior uso dos participantes do roteiro. Nele são encaminhados documentos mais importantes, como, por exemplo, contratos do roteiro em exposições e feiras. Percebeu-se que, através das entrevistas, poucos dos integrantes não comentaram sobre o uso desta ferramenta.

Quanto a Efetividade da Comunicação procurou-se definir, através de quatro ferramentas, como a comunicação na associação tem praticabilidade e funcionamento. Nesta macro categoria emergiram 4 sub-categorias, apresentadas na Imagem 4.

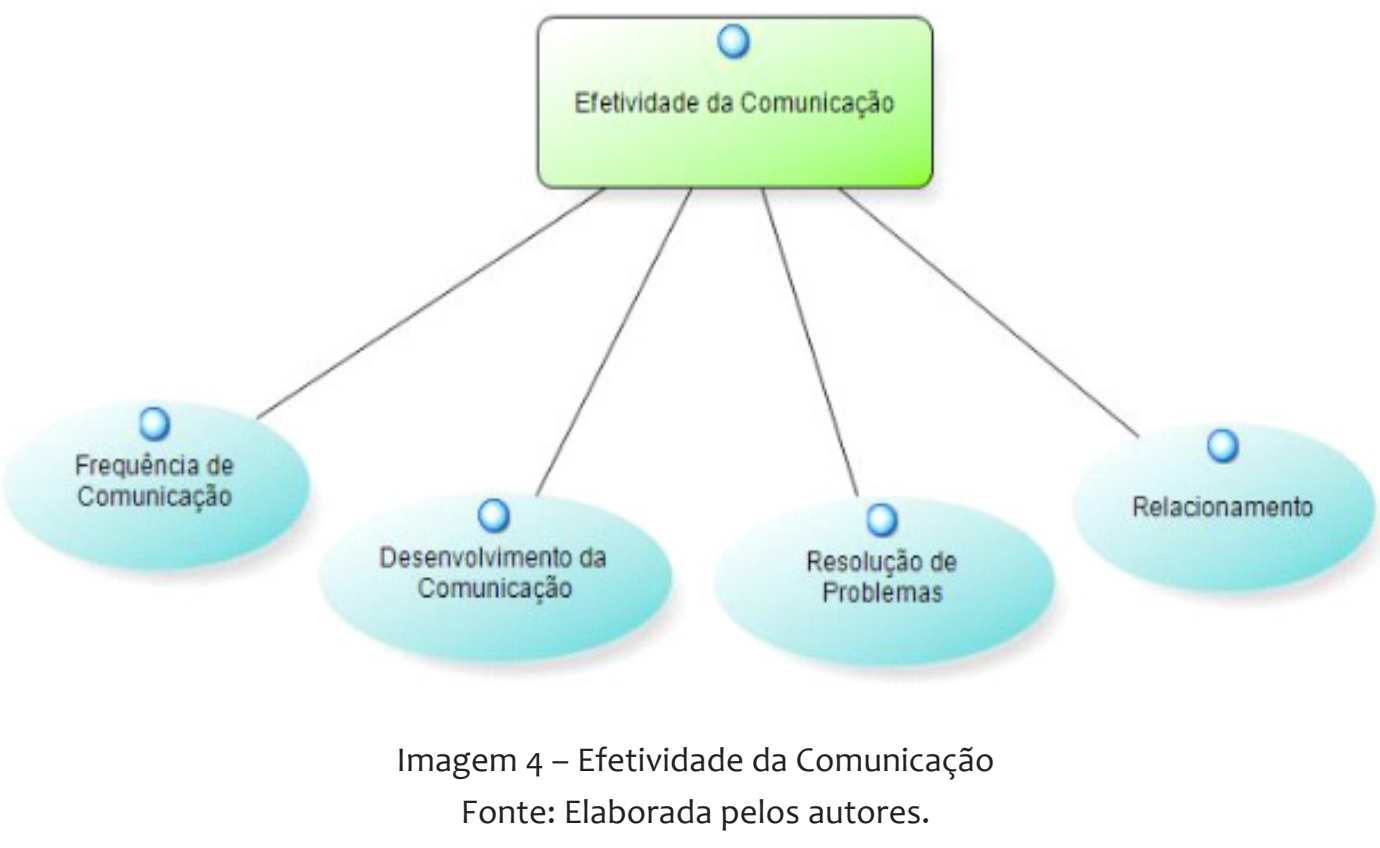

A "Frequência de Comunicação" apresenta a assiduidade os participantes do roteiro encontram para tomar decisões. Já o "Desenvolvimento de Rev.Cad.Comun. Santa Maria, v.20, n.3, art 6, p.136 de 145, set/dez.2016 
Comunicação" emergiu nas falas dos entrevistados em relação à fluência da comunicação no roteiro turístico Compassos da Mérica Mérica. Na observação do contexto abordado nas entrevistas, a "Resolução de Problemas" tratou de assuntos relacionados ao desenvolvimento da boa convivência a fim de sanar possíveis problemas que viessem a surgir no roteiro. Já a subcategoria "Relacionamento" abordou como se dá o convívio entre os participantes, a existência de uma interação positiva entre todos ou se existem aspectos negativos.

No conteúdo abordado nas entrevistas, percebe-se que os integrantes do Roteiro Compassos da Mérica Mérica se comunicam com frequência, houve bastante representatividade deste contexto nas entrevistas. Com isso, nota-se que todos eles procuram entrar em contato, difundir ideias, passar conhecimento para os demais integrantes. A boa comunicação é processo essencial para que a associação se desenvolva enquanto empreendimento, pois, é através dela que se gera o entendimento e o desenvolvimento de ações em conjunto. Em complemento, o desenvolvimento da comunicação buscou suscitar se ela se dá de forma adequada. Percebemos que, ela flui de maneira positiva, não são gerados ruídos com frequência. Porém, isso foi abordado por poucos entrevistados.

O Relacionamento apresentou várias características. Em sua maioria, os entrevistados que falaram sobre o assunto, disseram que o relacionamento é bom e que procuram sempre ajudar um ao outro. Nota-se que, pelo Roteiro ter se desenvolvido em propriedades próximas, já havia um relacionamento amigável entre todos os que participam do roteiro. Entrevistado 9 citou: " $\mathrm{A}$ interação é positiva, sempre cuidamos para manter uma boa relação" e, em acréscimo, o entrevistado 6 expõe: "Todos nos damos bem, principalmente por nos conhecermos de bastante tempo, é uma comunidade pequena.".

O resultado da entrevista, referenciando o Relacionamento do roteiro, foi possível verificar também que, por mais que haja um bom entendimento e boa relação entre todos os integrantes, ainda assim é gerada alguma discordância entre eles, mas isso se dá de maneira a não afetar o relacionamento. Entrevistado 3 complementa: "Em algumas vezes ocorrem certos desentendimentos, como em qualquer lugar, porque somos pessoas que possuem pensamentos diferentes.". 
Já a macro categoria Capital Social, explanou os aspectos que fundamentam o contexto de Capital Social. Comprometimento e Confiança são elementos essenciais para a fomentação do relacionamento e cooperação da associação. O objetivo comum apresenta a unidade de ferramentas em busca do benefício de todos os associados. A literatura reportou que o capital social é a ponte que mantém as instituições em contato entre si e as vincula ao cidadão visando à produção de bem comum (MARTI, 2004; BOURDIEU, 2001). Por isso, ao discutir o desenvolvimento de ferramentas do capital social identificou-se o comprometimento, confiança e democracia, facilita a cooperação espontânea, fazendo com que cada vez mais o capital seja rico e que o contato entre todos os envolvidos na associação tenha força, se tornando um diferencial perante outras organizações.

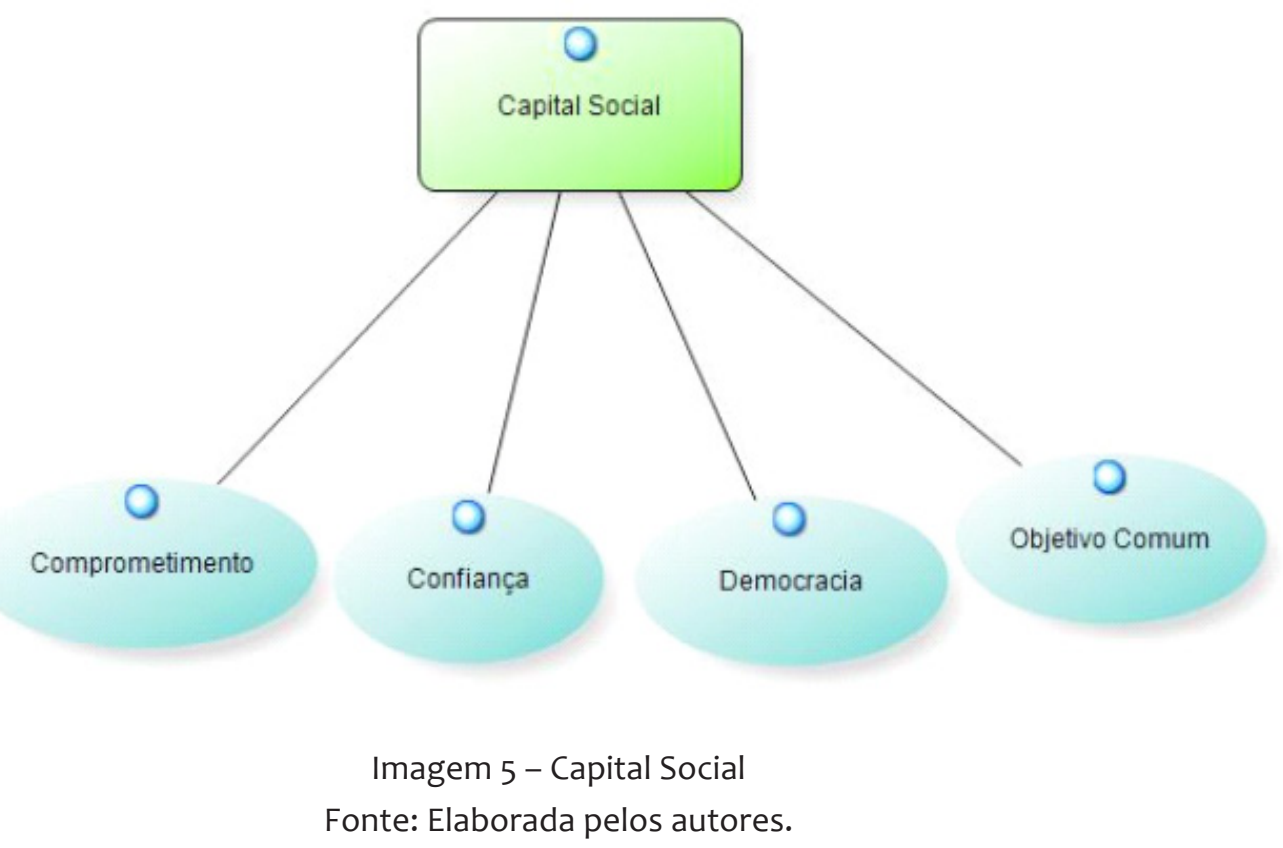

Foi possível verificar através da entrevista, ilustrado na Imagem 5, o roteiro turístico Compassos da Mérica Mérica possui, na sua essência, o desenvolvimento do Capital Social. E este se torna ferramenta de diferenciação perante os demais empreendimentos atuantes da mesma área. Sem ter o conhecimento do que é Capital Social, todos eles abordaram elementos que são essenciais para o seu desenvolvimento. Democracia, confiança, comprometimento e a busca pelo objetivo comum foram citados por, pelo menos cinco dos nove integrantes do roteiro. Nota-se que, a democracia é praticada, sendo lembrada por quase todos os integrantes. Eles difundem a ideia 
de que estão participando da associação para que todos tenham a oportunidade de trazer algo novo, ter a oportunidade de falar e explanar os seus conhecimentos, defendendo que toda contribuição é bem-vinda e as informações são discutidas em conjunto.

O Objetivo Comum é referenciado por praticamente todos os entrevistados, o que mostra que estão juntos para desenvolver, de forma efetiva, um benefício para todos os que fazem parte do Roteiro. Entrevistado 3 cita: "Os objetivos da associação e do desenvolvimento do roteiro é para benefício de todos os que participam dele", e o Entrevistado 9, também aborda o seguinte aspecto: "Toda ação tomada visa o crescimento do grupo".

Confiança e comprometimento são aspectos essenciais para o desenvolvimento do Capital Social. Putnam (2002) expõe que o aspecto da confiança é visto como o facilitador e viabilizador da vida social ao gerar e potencializar os recursos econômicos. Dessa forma, a confiança é alcançada a partir do conhecimento mútuo entre os membros da comunidade e em consequência da forte tradição de ação comunitária.

Foi possível perceber, ao longo da análise das entrevistas, que estas duas ferramentas são desenvolvidas junto ao roteiro fortemente. A partir de então, é possível desenhar a criação do Capital Social dentro do Roteiro. Entrevistado 4 cita: "A confiança é extremamente importante, foi o passo inicial para que montássemos a associação.”. Entrevistado 2 complementa: "[...] temos bastante confiança um no outro, porque sempre que alguém precisa, todos estão dispostos a ajudar e isso fez com que a associação desse certo.".

Ao se remeter as considerações de Watson e Papamarcos (2002) as quais destacam que uma abordagem que relaciona o capital social com o comprometimento organizacional sempre é promissora, percebeu-se que o comprometimento também se fez presente na maioria das entrevistas, um ponto forte que caracteriza ganho enérgico para a associação. O Entrevistado 8 menciona: "Não é fácil para que todos estejam sempre disponíveis, até porque todos têm bastante trabalho nas suas empresas; mas sempre que necessário, cada um procura ajudar", e, Entrevistado 7 complementa: "Todas as pessoas são comprometidas, todos procuram estar presentes nas reuniões e todos expõem as suas ideias.”.

Por fim, através das palavras citadas nas entrevistas, foi possível aferir que são identificados traços fortes do desenvolvimento do Capital

Rev.Cad.Comun. Santa Maria, v.20, n.3, art 6, p.139 de 145, set/dez.2016 
Social no Roteiro Turístico Compassos da Mérica Mérica. Todos os entrevistados abordaram através de alguma fala, algum aspecto que remete à construção do mesmo. Por serem empreendimentos não muito grandes, foi possível constatar a humildade e a vontade de todos de crescerem enquanto associação e ajudar sempre o desenvolvimento do roteiro.

\section{Considerações finais}

Com o objetivo de explorar o papel das atividades de Relações Públicas na formação de capital social em associações enoturísticas o artigo buscou analisar aspectos distintos da das variáveis econômicas, e avaliando assim os ativos intangíveis do roteiro enoturístico Compassos da Mérica Mérica, na Serra Gaúcha.

Com base nos objetivos propostos e nas análises dos resultados obtidos com os entrevistados, foi possível verificar que todo o roteiro é embasado no desenvolvimento do bem comum, partindo do argumento de que o mesmo foi criado com o intuito de que os empreendimentos da localidade pudessem aumentar a sua renda. Por ser uma localidade pequena, todos os integrantes foram comprometidos e engajados. Também foi possível verificar que confiabilidade, comprometimento e democracia são critérios que todos salientaram de forma praticamente unânime, como importantes. Segundo Coleman (1990) o capital social é caracterizado como os atributos de uma organização, como a confiança, normas e redes, facilitam ações coordenadas e melhoram a eficiência da sociedade.

Considerada peça fundamental de qualquer relacionamento, a comunicação precisa ser desenvolvida de forma coerente entre todos que fazem parte da organização, para que haja entendimento e um bom relacionamento. Partindo dessa premissa, foi possível verificar a comunicação como peça chave para o desenvolvimento do Capital Social, tendo em vista que este considera a confiabilidade, comprometimento e lealdade como construtos importantes para o seu progresso.

A comunicação no roteiro é desenvolvida, em sua maior parte, informalmente. Foi possível averiguar que todos os integrantes utilizam ferramentas informais de comunicação, como, por exemplo, aplicativos de envio de mensagens pelo celular. Comunicam-se com frequência e reuniões são realizadas mensalmente para um contato face-a-face. É possí- 
vel destacar essa comunicação quase toda informal como um empecilho para o Roteiro quando há a necessidade de desenvolvimento de ações com um grau de formalidade maior; como, por exemplo, em apresentações de projetos para entidades de classe do setor vitivinícola.

A formação do Capita Social depende muito do relacionamento que é mantido dentro das organizações, ele pode ser definido como um conjunto de redes de comunicação e cooperação que facilitam a construção de ações coletivas. No caso do estudo realizado, o Roteiro Turístico Compassos da Mérica Mérica, possui o desenvolvimento do Capital Social como ferramenta diferencial.

Ao entender que exercer RP vai além de executar normalmente suas atividades, mas também pode contribuir na formação de redes de relacionamento e democracia, estamos, implicitamente, sugerindo uma nova atuação do profissional de comunicação, que atuará focado na concepção de crescimento humano a fim de participar do desenvolvimento de capital social. As organizações que esperam conquistar vantagens competitivas precisam desenvolver as pessoas para que entendam a importância da comunicação.

As RP podem promover o Capital Social através do desenvolvimento da comunicação nas redes. Putnam (1993) coloca que as normas partiIhadas e a confiança facilitam a coordenação e a cooperação visando um proveito mútuo. Para que as normas sejam partilhadas é preciso que haja uma comunicação interna desenvolvida de forma eficiente. É importante que ela também seja dirigida externamente de forma efetiva, a fim de atingir os públicos que possuem interesse em roteiros enoturísticos.

Para isso, a relação entre capital social e o Roteiro Turístico Compassos da Mérica Mérica, se mostra eficiente ao ser incorporada à visão de RP, já que esta desperta no indivíduo o sentimento de buscar formas para gerar o crescimento em grupo. Da mesma maneira, as atividades de Rps possibilitam que os interesses das associações de enoturismo sejam ouvidos. É possível enxergar, portanto, que a articulação entre RPs, capital social e enoturismo pode contribuir para o fomento dos empreendimentos associados.

Visando o crescimento de um todo enquanto Roteiro, é necessário que haja um maior engajamento para participação de eventos direcionados à área enoturística, para que ganhem notoriedade no ramo onde atuam e estejam por dentro de tudo que está sendo desenvolvido nesta

Rev.Cad.Comun. Santa Maria, v.20, n.3, art 6, p.141 de 145, set/dez.2016 
CADERNOS DE COMUNICAÇÃO

UNIVERSIDADE FEDERAL DE SANTA MARIA

área. Verifica-se aqui, a possibilidade de atuação do profissional de Relações Públicas, que tomará conta do processo de reconhecimento de marca e o relacionamento com parceiros potenciais para o roteiro de enoturismo.

Rev.Cad.Comun. Santa Maria, v.20, n.3, art 6, p.142 de 145, set/dez.2016 


\section{REFERÊNCIAS}

ALBAGLI, S.; MACIEL, M L. Capital social e desenvolvimento local. Pequena empresa: cooperação e desenvolvimento local. Rio de Janeiro: Relume Dumará, p. 423-440, 2003.

ARAÚJO, U. P.et al. Capital Social em um Comcórsio de Pesquisa/Social Capital. In: A Research Consortium/Capital Social en un Consorcio de Investigación.Revista de Administração de Empresas, v. 50, n. 4, p. 411, 2010.

BOTAN, C. H.; H., Vincent. Public relations in a new age. Public relations theory II, p. 1-18, 2006.

BOURDIEU, P. O Poder simbólico. 4. ed. São Paulo: Bertrand Brasil, 2001. 311p.

BOURDIEU, P. 1. Le capital social. Notes provisoires. Recherches/MAUSS, p. 29-34, 2006.

CHARTERS, S.; ALI-KNIGHT, J. Who is the wine tourist? Tourism management, v. 23, n. 3, p. 311-319, 2002.

COLEMAN, J. S. Foundations of social theory. Cambridge: Harvard University Press, 1990.

DALLANHOL, E. B.; TONINI, H. Enoturismo. São Paulo: Aleph, 2012

DODD, M. D.; BRUMMETTE, J.; HAZLETON, V. A social capital approach: An examination of Putnam's civic engagement and public relations roles. Public Relations Review, v. 41, n. 4, p. 472-479, 2015.

DUBRULE, P. l'Oenotourisme: une valorisation des produits et du patrimoine vitivinicoles. rapport pour le Ministre de l'Agriculture et de la Pêche et au Ministre du Tourisme, 2007.

FLICK, U. Desenho da pesquisa qualitativa. Coleção Pesquisa qualitativa. Bookman Editora, 2009.

FUKUYAMA, F. Confiança. Valores sociais e criação de prosperidade. Lisboa: Gradiva, 1996.

GENARI, D.; MACKE, J.; FACCIN, K. Mensuração do capital social organizacional em redes de indústrias vitivinícolas brasileiras. Revista Base, v. 9, n. 1, p. 53-67, 2012.

GIBBS, G. Análise de dados qualitativos. Coleção pesquisa qualitativa. Bookman Editora, 2009.

GROOTAERT, C. Measuring social capital: An integrated questionnaire. World Bank Publications, 2004.

GRUNIG, J. E. Excellence in public relations and communication management. Routledge, 2013.

HABERMAS, J. The structural transformation of the public sphere: An inquiry into a category of bourgeois society. MIT press, 1991.

HALL, C. M. et al. Food tourism around the world. Routledge, 2004.

HANIFAN, L. J. The rural school community center.Annals of the American Academy of political and social science, v. 67, p. 130-138, 1916.

MARTI, J.M.V. Social capital benchmarking system: profiting from social capital when building network organizations. Journal of Intellectual Capital, v. 5, n. 3, p. 426-442, 2004.

MATOS, H. Capital social e comunicação: interfaces e articulações. São Paulo: Summus, 2009.

MILANI, C. Teorias do Capital Social e Desenvolvimento Local: lições a partir da ex-

Rev.Cad.Comun. Santa Maria, v.20, n.3, art 6, p.143 de 145, set/dez.2016 
periência de Pintadas (Bahia, Brasil). In: IV Conferência Regional ISTR-LAC, São José, Costa Rica. 2003.

PUTNAM, R. D. Comunidade e democracia: a experiência da Itália moderna. FGV Editora, 2000.

VALDUGA, V. O processo de desenvolvimento do enoturismo no Vale dos Vinhedos. 2014 .

YANG, A.; TAYLOR, M. The relationship between the professionalization of public relations, societal social capital and democracy: Evidence from a cross-national study. Public Relations Review, v. 39, n. 4, p. 257-270, 2013.

YIN, R.K. Estudo de caso: planejamento e métodos. 3. ed. Porto Alegre: Bookman, 2005.

WOOLCOCK, M. The rise and routinization of social capital, 1988-2008.Annual review of political science, v. 13, p. 469-487, 2010. 


\section{Resumo sobre autores:}

Ediane Bassanesi

Graduanda em Comunicação Social - Habilitação em Relações Públicas pela Universidade de Caxias do Sul

E-mail edibassanesi@hotmail.com

Eduardo Robini da Silva

Mestre em Administração pela Universidade de Caxias do Sul

E-mail: eduardorobini@gmail.com

Fernanda Pauletto D'Arrigo

Mestre em Administração pela Universidade de Caxias do Sul.

E-mail: fernanda.darrigo@gmail.com

Ana Cristina Fachinelli

Doutora em Ciências da Comunicação e da Informação pela Universidade de Poitier. É docente do Programa de Pós-Graduação em Administração na Universidade de Caxias do Sul.

E-mail: afachinelli@gmail.com 